\title{
Aproximación empírica alos determinantes de la Inversión Extranjera Directa en el sector manufacturero colombiano (1978-2002)
}

\author{
Angélica Hernández, Góez \\ Especialização em Controladoria e Finanças, Centro Universitário Senac, Sau Pablo, Brasil. Economista, Universidad \\ Nacionalde Colombia (Sede Medellín),Colombia.E-mail: angelhez@hotmail.com; ahernan0@unal.edu.co
}

\begin{abstract}
Resumen
En este artículo se pretende estimar a través de un análisis de regresión, cuáles son los principales determinantes que influyen en las corporaciones transnacionales a invertir en el sector manufacturero colombiano. Para esto, se divide el estudio en tres partes: la primera muestra la evolución del sector manufacturero colombiano; la segunda muestra el comportamiento de los flujos de IED a nivel mundial, nacional, su comportamiento a nivel sectorial en Colombia y se realiza una aproximación teórica y una estimación econométrica; y por último, se realizan las conclusiones.
\end{abstract}

Palabras clave: Inversión extranjera directa, Industria manufacturera en Colombia.

Abstract

This article aims to estimate through regression analysis, what are the main determinants that influencing transnational corporations to invest in the Colombian manufacturing sector. This study is divided into three parts: the first shows the evolution of Colombian manufacturing sector, the second shows the behavior of FDI flows at the global, national, sectoral-level behavior in Colombia and a theoretical approach and econometric estimation, and finally conclusions are made.

Key words: Forest direct investment, Colombian manufacturing industry

\section{Résumé}

Cet article vise à estimer grâce à l'analyse de régression, quels sont les principaux déterminants qui influent sur les sociétés transnationales à investir dans le secteur de la fabrication sont colombien. Pour cette étude est divisée en trois parties, la première montre l'évolution du secteur de la fabrication de la Colombie; le deuxième montre le comportement des flux d'IDE au comportement global, national, sectoriel niveau en Colombie et une approche théorique et une estimation économétrique est réalisée; et enfin les conclusions sont faites.

Mots-clés: Les investissementsdirectsétrangers, L’industriemanufacturière en Colombie. 



\section{Aproximación empírica a los determinantes de la Inversión Extranjera Directa en el sector manufacturero colombiano (1978-2002)*}

Angélica Hernández Góez

\section{LA INDUSTRIA MANUFACTURERA COLOMBIANA ENTRE 1978 Y 2002}

\subsection{Evolución de la Industria Manufacturera Colombiana}

Desde la época de la Posguerra hasta mediados de los años 70's, el sector manufacturero fue el dinamizador de la economía colombiana con una tasa de crecimiento del 7.5\% entre 1929 y 1973 (Echavarría, 2007); un aumento del valor agregado de esta industria a precios de 1970 de $377 \%$ y el incremento a $40.6 \%$ de participación de las exportaciones industriales en el total de exportaciones del país (DNP, 1977) indican el grado de desarrollo que tuvo el sector durante este período por medio de la industrialización por sustitución de importaciones.

Este proceso de industrialización, a pesar de haber sido implementado por condiciones de orden externo y coyuntural ${ }^{1}$ en América Latina en general y en Colombia en particular, alcanzó varios logros, por ejemplo, la oferta de bienes domésticos se incrementó e inclusive hubo autosuficiencia de bienes industriales ${ }^{2}$; se obtuvieron incrementos en la producción de bienes intermedios y de bienes de capital, mientras que entre 1950 y 1952 la producción doméstica de los primeros era del $61 \%$, ya para 1974 era del orden de $78.3 \%$; además, las importaciones de bienes de capital ${ }^{3}$ disminuyeron durante el mismo período aproximadamente 25 puntos porcentuales.

* El artículo es producto de investigación del proyecto: Inversión extranjera directa de Spillovers de productividad en las empresas manufactureras colombianas. Grupo de Economía Internacional de la Escuela de Economía. Universidad Nacional de Colombia. Sede Medellín. Colombia.

1 La industrialización por sustitución de importaciones “...fue esencialmente una acción espontánea de los inversionistas locales inducida por un proceso de consolidación del capitalismo. Además, las frecuentes perturbaciones externas del período actuaron como catalizadoras del proceso: la volatilidad internacional generó crisis, pero también oportunidades que fueron aprovechadas para el desarrollo industrial del país" (Ortiz, Uribe y Vivas, 2009, p. 27).

2 Por ejemplo para los años de 1972 a 1974 la oferta de textiles producidos nacionalmente alcanzaba un $97.6 \%$.

3 Para esquematizar, los bienes intermedios están compuestos por los siguientes sectores: Madera, papel y sus productos, imprentas y editoriales, productos de caucho, sustancias y productos químicos, derivados del petróleo y del carbón, minerales no metálicos, industrias metálicas básicas y productos no metálicos. A los bienes de capital pertenecen los sectores de Maquinaria no eléctrica, maquinaria eléctrica, equipo de transporte. 
Tabla 1. Porcentaje de Exportaciones Tradicionales y no Tradicionales entre el Total de Exportaciones

\begin{tabular}{ccccccccccc}
\hline & 1967 & 1968 & 1969 & 1970 & 1971 & 1972 & 1973 & 1974 & 1975 & 1976 \\
\hline $\begin{array}{c}\text { Export. No } \\
\text { Tradicionales }\end{array}$ & $22,14 \%$ & $28,15 \%$ & $30,73 \%$ & $28,99 \%$ & $34,91 \%$ & $42,13 \%$ & $45,79 \%$ & $45,98 \%$ & $47,49 \%$ & $37,90 \%$ \\
\hline $\begin{array}{c}\text { Exportaciones } \\
\text { Tradicionales }\end{array}$ & $77,86 \%$ & $71,85 \%$ & $69,27 \%$ & $71,01 \%$ & $65,09 \%$ & $57,87 \%$ & $54,21 \%$ & $54,02 \%$ & $52,51 \%$ & $62,10 \%$ \\
\hline
\end{tabular}

Fuente: DNP

Figura 1. Tasa de Variación Anual

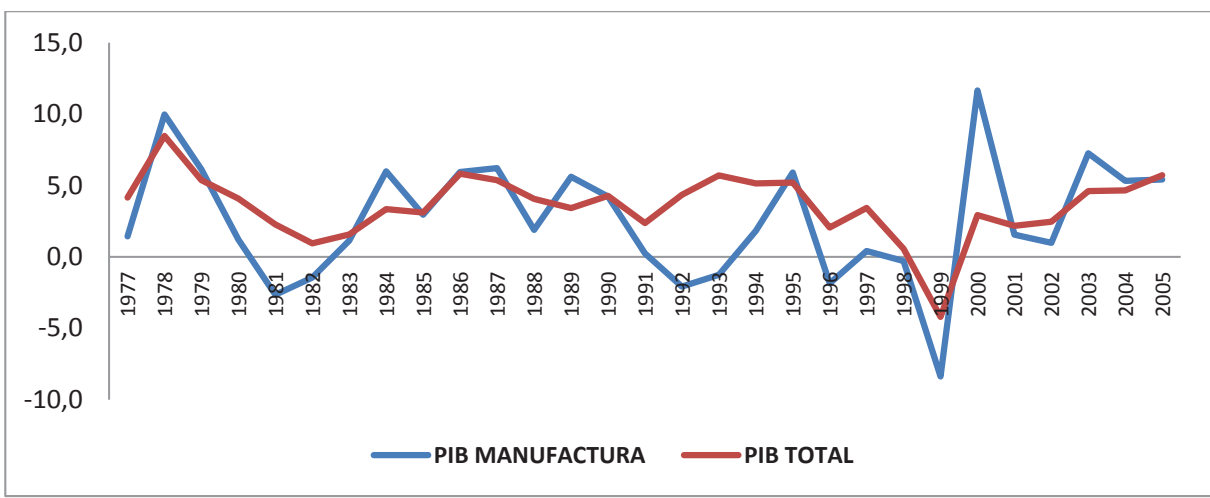

Fuente: CEPAL.

Después de presenciar un período de crecimiento económico sostenido hasta mediados de los años setentas cuyo uno de sus principales resultados fue la expansión de la oferta de bienes exportables (ver Tabla 1), el proceso de crecimiento de la economía colombiana comenzó a desacelerarse a principios de los años ochenta. En la Figura 1 se aprecia la caída en la tasa de crecimiento del PIB total y el manufacturero desde 1977 a 2005, período en el cual las caídas más pronunciadas se presentaron entre 1978-1981, 1989-1992 y 1995-1999, siendo más fuertes para el sector manufacturero que para el resto de la economía.

A partir del período 1978-1981 la economía colombiana aunque presentó períodos de recuperación, la tasa de crecimiento no presentó niveles iguales o superiores a los observados entre 1950 y 1975, y el sector manufacturero dejó de ser el motor de crecimiento. Esta última consecuencia fue provocada por diferentes razones, una de ellas se debe al tipo de acumulación de capital que se desarrolló en la estructura económica colombiana, que en términos del profesor Misas (2002, p. 302) se define como: 
Acumulación Extensiva: es el desarrollo del capitalismo que conquista nuevas ramas y nuevos mercados y extiende sus relaciones de producción a nuevos ámbitos de la actividad económica, sin que se modifiquen considerablemente las condiciones de producción y la eficiencia del trabajo o el capital.

Acumulación Intensiva: "las condiciones de producción se transforman sistemáticamente, buscando incrementar la productividad aparente del trabajo. Las nuevas inversiones se ven reflejadas especialmente en un aumento del "Stock" de capital por trabajador.

\subsection{El Sector Manufacturero en el Proceso de Apertura}

A partir de la posguerra el modo de producción fordista, soportado por el Estado de Bienestar Keynesiano, fue el que se instauró como forma de acumulación del capital y se caracterizó por "promover el pleno empleo en una economía nacional relativamente cerrada, principalmente a través de la demanda, y generalizar las normas de consumo de masas, a través de los derechos al bienestar y de nuevas formas de consumo colectivo" (Jessop, 1999, p. 65) . $^{4}$

Sin embargo, desde mediados de los años setentas a nivel mundial este régimen de acumulación mostró desarticulaciones frente a las nuevas tendencias técnicoeconómicas. El nuevo paradigma que se comenzó a implementar se fundamentó en la apropiación del conocimiento tecnológico y científico y el surgimiento de nuevas tecnologías para el incremento y expansión económica; paralelamente hay un mayor interés por el proceso que por el mismo producto, la producción se basa en la flexibilización, la innovación y en patrones de consumo que se modifican rápidamente.

En relación a lo anterior, las funciones del Estado se modifican en procura de elevar, o mantener los niveles de acumulación de capital. En efecto, el dinamismo de los flujos de capital que impulsa la internacionalización de las economías disminuye la acción reguladora y promotora del Estado, debido a que es presionado por sistemas estatales de orden supranacional y por las mismas regiones existentes dentro de éste. "La nueva forma de regulación emplea un discurso diferente que hace hincapié en el neoliberalismo para promover una transición guiada por el mercado hacia el nuevo régimen económico" (Jessop, 1999, p. 87).

Es bajo este contexto que se implementa el proceso de modernización del sector industrial colombiano, el cual se debía basar en la apertura comercial del país a los flujos internacionales de capitales y mercancías. La estrategia supuso entonces "que abrir la economía al mercado mundial permitirá la entrada de productos

4 Se entiende por Fordismo el régimen de acumulación que se caracteriza porque la organización del trabajo propende por la división de las tareas, la mecanización de los procesos productivos; y fundamentalmente porque el proceso dinámico de ajuste entre la producción y la demanda, debe llevarse a cabo esencialmente dentro de un espacio nacional" (Misas; 2002, p. 311). 
importados y el establecimiento de industrias extranjeras en el país, así como que al contar con el acceso a mercados foráneos mucho más amplios, los empresarios nacionales reaccionarian" (Zerda, 1992, p. 20). Lo que se produce es un nuevo modelo de desarrollo que se fundamenta en la internacionalización de la economía, la apropiación del conocimiento y las tecnologías, la flexibilización y la poca injerencia del Estado.

Por lo tanto, este cambio en la estrategia de desarrollo del país buscó incrementar la productividad y la competitividad apoyándose en el comercio exterior. En este sentido, son los Gobiernos de Virgilio Barco (1986-1990) y de César Gaviria (1991-1994) los que establecen el marco jurídico y reglamentario para legitimar la mencionada estrategia. En materia económica abren la cuenta de capitales para que el capital financiero ingrese con mínimas trabas, desregulan el mercado financiero, flexibilizan el mercado laboral y disminuyen considerablemente los aranceles y subsidios que protegían a la industria manufacturera.

Figura 2. Balanza comercial

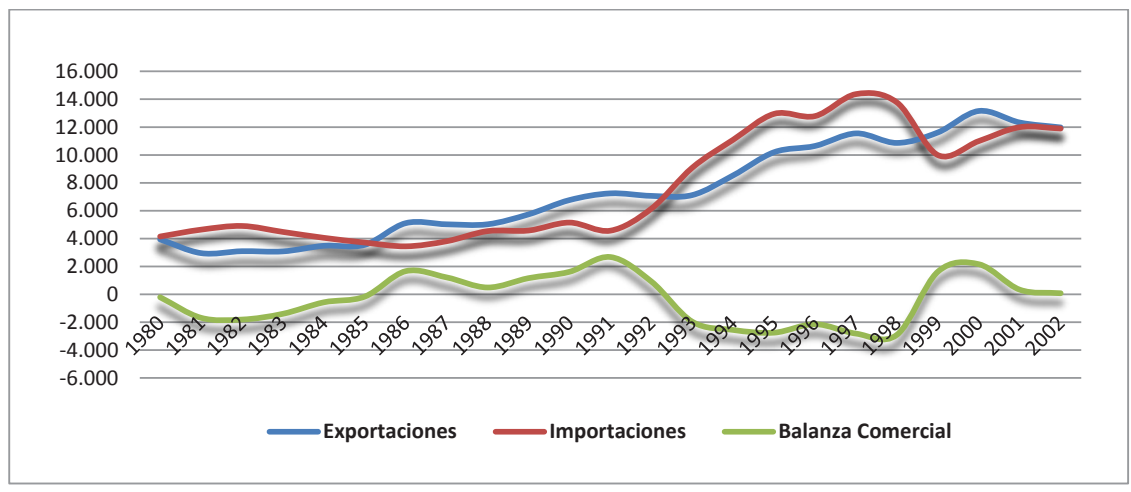

Fuente: DANE. Valores en Millones de Dólares FOB.

Como se expuso anteriormente, la fuerte dependencia del dinamismo de la economía colombiana a las exportaciones de café no se pudo resolver por medio de la sustitución de importaciones. En la Figura 2, se puede observar el deterioro que tuvo la Balanza Comercial entre 1980 y 1985 aproximadamente, debido a la caída de los precios internacionales del mencionado producto, a la reducción de las exportaciones menores y la apreciación del tipo de cambio que estimuló el ingreso de bienes importados, comprados principalmente por el sector público.

Este déficit comercial que para 1982 alcanzaba los 1.776 millones de dólares se complicó debido a la crisis financiera internacional y al cierre de las exportaciones colombianas en Ecuador y Venezuela. Aunado a la situación anterior, otro problema 
que afectó el desenvolvimiento de la economía colombiana fue el incremento de la tasa de inflación medida por el IPC, la cual alcanzó un nivel máximo de $26.4 \%$ en 1982; el principal motivo de este incremento fue el alza de los precios de los alimentos, en ese mismo año alcanzaron a llegar a 28.5\% (Perry, 1989, p. 196).

Para contener el crecimiento de la tasa de inflación, el Gobierno redujo la inversión del sector público pasando de 4.1 en 1980 a 2.9 en 1984. A partir de este año con la adopción del Consenso de Washington, la prioridad del país fue mantener una relación armónica entre la tasa de cambio, la inflación y la reducción del déficit fiscal.

En los primeros años de la década del noventa se adelantan las políticas económicas que iban a hacer implementadas de manera gradual, entre estas se encuentran la disminución de la tarifa de arancelaría, las reformas financieras introducidas por la Ley 45 de 1990 y la Ley 35 de 1993 cuyos propósitos principales fueron liberar las tasas de interés para depósitos de ahorro y crédito hipotecario y limitar la intervención del Banco Central en esas tasas, la adopción de un nuevo régimen cambiario y de un nuevo patrón de comercio introducido por la Ley 9 y la Ley 7 de 1991.

Los efectos producidos por el cambio de modelo en la economía colombiana han sido documentados por diferentes autores (Misas, 2002; Garay, 1998; Poveda, 2002) en las referencias dice 2005, revisar si es la misma obra a la que se hace referencia y arreglar, si no es la misma se debe agregar esta obra a la lista de referencias). Aquí se hará mención a los efectos más importantes que impactaron al sector manufacturero.

Entre 1990 y 1995 el PIB total creció a un ritmo promedio de $4.5 \%$ mientras que el PIB industrial lo hizo a una razón de $1.9 \%$. La liberalización del sector externo asociada a la cuenta de capitales, junto con la disminución de aránceles y de subsidios estimularon el ingreso de divisas que provenían del narcotráfico y de actividades ilícitas revaluando el peso y por ende, abaratando el costo de los bienes importados; su resultado fue el incremento de la participación de los bienes de capital en el total de importaciones del país pasando de 55,3\% a 61,4\% en el período 1981-1989 y 1991 2001 respectivamente. Un comportamiento diferente se observó en las exportaciones del mismo tipo de bienes, que aunque aumentaron no lo hicieron al mismo ritmo al pasar de $10,2 \%$ a $19,5 \%$ (Echavarría y Villamizar, 2007).

En la Figura 2 se puede apreciar el incremento tanto de las importaciones y de las exportaciones a partir de 1991. Sin embargo, las primeras lo hacen en una proporción mayor que las últimas; deteriorando de esta forma la balanza comercial del país.

Lo anterior agudizó los problemas del sector de bienes transables, específicamente la agricultura y la manufacturera, debido a que la industria colombiana no iba a la par con los nuevos requerimientos que en materia tecnológica el nuevo paradigma de desarrollo estaba implementando. Como resultado, se produjo una caída en la participación del sector manufacturero aproximadamente de tres puntos porcentuales dentro del PIB; más crónica fue la caída del sector agropecuario que disminuyó su participación cerca de diez puntos porcentuales. La Figura 3 muestra la evolución y las modificaciones que ha generado este proceso, por ejemplo, el sector 
servicios (comercio, restaurantes, transporte y los servicios financieros) aumentó su participación dentro del PIB alrededor de cinco puntos porcentuales.

Figura 3. Participación promedio porcentual por clase de actividad económica dentro del PIB

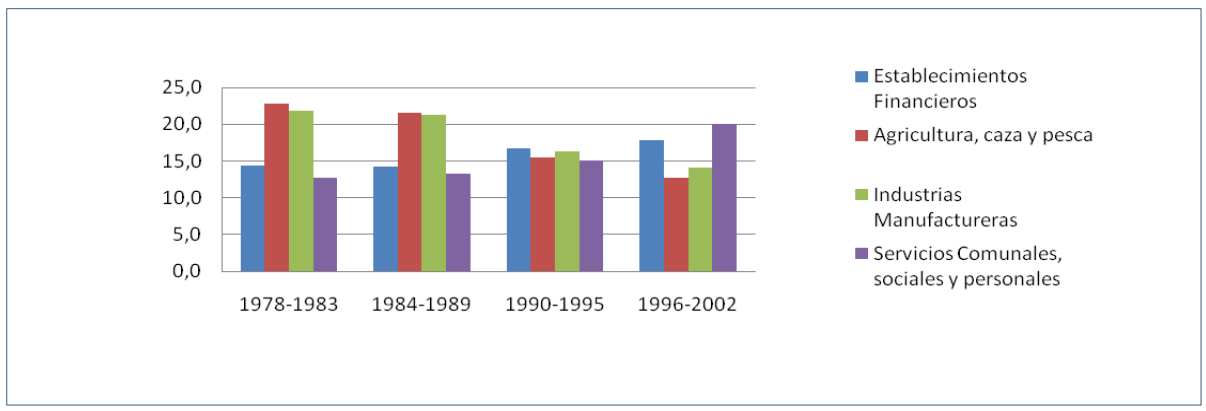

Fuente: CEPAL.

No obstante, respecto al empleo industrial el valor agregado creció a una tasa del 7.9\%, la remuneración salarial en la industria (salarios + prestaciones) que entre 1975 y 1980 crecía a razón de 5.3\%, para el período 1991 - 1995 lo hizo a una tasa de 1,2\%. Para la segunda mitad de los años noventa el sector manufacturero seguía con patrones de comportamiento similares a los del proceso de apertura. Los subsectores que contribuían con más del 3\% de las exportaciones en el período 1990-1995 permanecieron invariables entre 1996 y 2002; entre estos se encuentran los tejidos de punto y de ganchillo, los productos refinados del petróleo, los productos químicos básicos y elaborados, este último tuvo una participación considerable al pasar de $6.36 \%$ en 1990 a 9,93\% en el 2002 (DANE, Cuentas Nacionales).

Por su parte las exportaciones de café que contribuían en 1990 con el $26.48 \%$ de las exportaciones, ya en el 2002 tenían una participación de 11,3\%; su lugar fue ocupado por las exportaciones de petróleo con una participación de 11,82\% en 1991 pasando por su nivel máximo de $22,35 \%$ en 1999 , para bajar nuevamente a $14,47 \%$ en el 2002; la participación en el incremento de las exportaciones de petróleo crudo se debe a los nuevos descubrimientos de yacimientos petrolíferos en 1993 y 1994.

La estructura de consumo que heredó el país gracias a la sustitución de importaciones se enfoca más en el consumo de bienes y servicios producidos en el mercado interno. Con el proceso de apertura se consideró que era el mercado exterior el que iba a dinamizar la demanda y por ende la producción de bienes y servicios, como se observa en la Figura 4 este patrón de comportamiento no se ha modificado, ya que aproximadamente el 45\% de la demanda de bienes y servicios desde 1990 hasta el 2002 es realizada por personas que viven al interior del país, igualmente la demanda del resto del mundo se ha mantenido constante (en menos del 10\%) durante ese mismo período de tiempo. 
Figura 4. Composición de la demanda de bienes y servicios

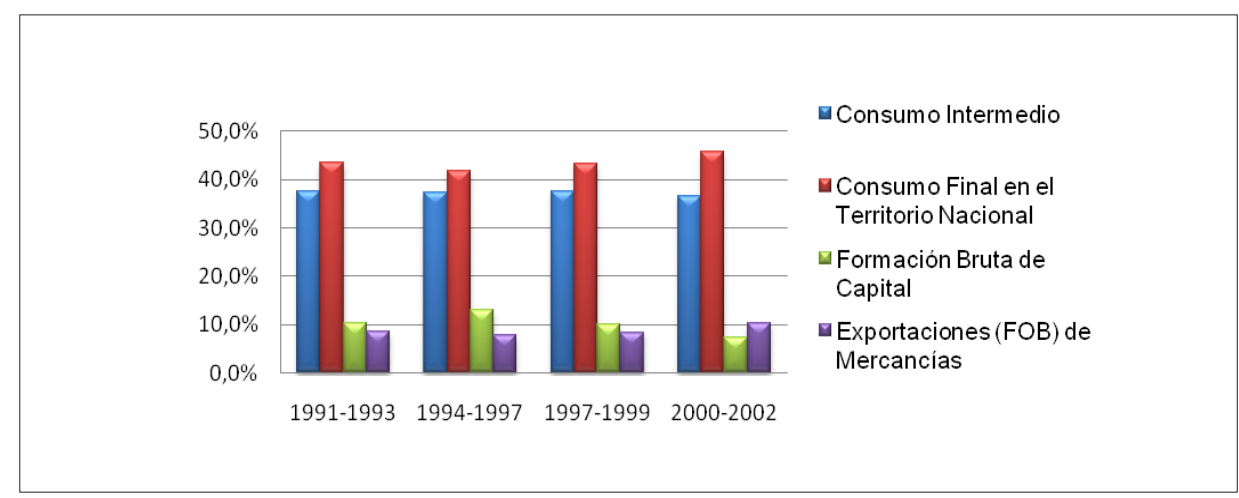

Fuente: DANE.

\subsection{Crisis de los Años 1998 y 1999}

Los últimos años del siglo XX reflejaron el desajuste estructural en la política económica del país: la tasa de crecimiento del PIB total se desaceleró hasta caer a un nivel de 7,08\% en 1999, la tasa de desempleo aumentó en las siete principales ciudades del país al pasar de $12 \%$ en 1998 a 15\% en 1999. En el sector industrial manufacturero el empleo industrial descendió a una tasa de $2.7 \%$, la producción de la industria sin trilla de café reportó una pérdida de 13.3\% en enero de 1999 (ANDI, 1999).

Esta caída en el nivel de actividad económica fue motivada por el alza en el nivel de consumo a principios de los años noventa. Este aumento del consumo se provocó principalmente por la revaluación del tipo de cambio incrementando el poder adquisitivo del salario nacional respecto al internacional, lo cual produjo el alza en términos reales de las importaciones.

Como se dijo anteriormente, la liberalización de la cuenta de capitales y del sector financiero estimularon el ingreso de dineros producto del narcotráfico. Junto a esto, el hallazgo de nuevos yacimientos petrolíferos como los yacimientos de Cusiana y Caño Limón incrementaron las exportaciones de petróleo crudo aproximadamente en seis puntos porcentuales. El auge de las exportaciones de petróleo facilitó la adquisición de préstamos por parte de la banca nacional y del gobierno.

La facilidad de acceso a préstamos inyectó liquidez al sistema y para el sector público esto se reflejó en un aumento de la inversión pasando de $6.1 \%$ del PIB en 1991 a un 11\% del PIB en 1997; esto con el propósito de financiar los nuevos compromisos sociales adquiridos por la Constitución Política de 1991. Para el sector privado significó expectativas de un ingreso mayor permanente. Sin embargo, se desestimuló el ahorro nacional, como porcentaje del PIB pasando de $22.7 \%$ en 1991 a $15.5 \%$ en 1995 (ANDI, 1996). 
Exceptuando las empresas que incrementaron el nivel de importaciones de bienes de capital, el problema radicó en que la mayoría del consumo se dirigió al sector bienes de consumo no durables y al sector de bienes no transables (construcción, vivienda), por ejemplo, las familias compraron viviendas por el sistema UPAC y el sector público financió un déficit de carácter permanente.

El aumento en la inversión en el sector de bienes no transables apreció la tasa de cambio abaratando nuevamente las importaciones de bienes de consumo durable y no durable; se produjo de nuevo un incremento en la demanda doméstica. El alza en el consumo se efectúo sin medirse respecto a las reales posibilidades de pago que tenían los agentes en la economía.

Al no tener respaldo real para cancelar el alto consumo y endeudamiento, una modificación en la política económica produciría fuertes impactos a los agentes económicos. Entre 1996 y 1997 la economía colombiana presenta signos de recesión, para resolverla se acogieron políticas de corto plazo que buscaron incrementar el gasto del sector público y privado disminuyendo la tasa de interés y aumentando la oferta de crédito.

No obstante, los objetivos se lograron; esta medida afectó el tipo de cambio acelerando la depreciación del peso y creando un exceso de liquidez; el primero de estos efectos fue interpretado como buen resultado para el sector exportador, no obstante, el segundo efecto podría crear presiones inflacionarias a lo cual el Banco de la República respondió con el alza de las tasas de interés. La medida se adopta en un momento en el que la política económica deja de ser manejable por la autoridad monetaria (Echeverri, 1999). Entre 1997 y 1998 lo que se ocasiona es una progresiva alza de las tasas de interés, tanto las tasas activas y pasivas se incrementaron rápidamente hasta llegar a 44,5\% y 32,5\% respectivamente (Banco de la República, 2005).

Figura 5. Evolución de la tasa activa y pasiva

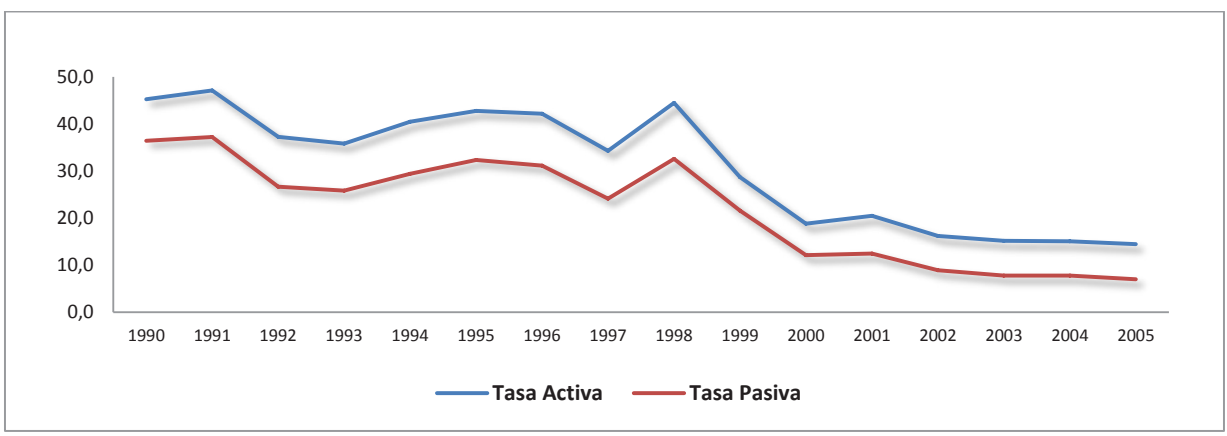

Fuente: Banco de la República (2005), Superintendencia Bancaria. 
La Tasa Pasiva Corresponde a la tasa de captación de CDT reportada por bancos, corporaciones financieras y compañías de financiamiento comercial.

Con el propósito de proteger la banda cambiaria el Banco Central se encuentra en una disyuntiva de mantener el tipo de cambio con tasas de interés altas o mantener el tipo de cambio bajando la tasa de interés. Esta inconsistencia en la política monetaria incrementa repentinamente la tasa de interés reventando la burbuja especulativa de períodos anteriores ocasionando una de las crisis más profundas que ha tenido la historia económica del país.

Para los hogares el precio de la vivienda se desvalorizó y la tasa de interés se incrementó aumentando la deuda hipotecaria, para las empresas la cartera aumentó y los índices de liquidez disminuyeron, el aumento de la tasa de interés incrementó los pasivos de las firmas y el crédito del sector bancario disminuyó por posibilidades de riesgo en el pago de este.

El resultado fue entonces, como se dijo anteriormente, aumento en el nivel de desempleo y pérdida en el nivel de crecimiento de la economía. Para la industria manufacturera la crisis significó reducción en la producción de $-6.1 \%$ concentrándose en los subsectores de bebidas, plásticos, otros químicos, imprentas, calzado, metalmecánico, en los bienes intermedios producidos para el sector de la construcción y en los bienes de capital cuyo crecimiento pasó de 27,3\% a -1.3\%.; subutilización de la capacidad instalada, ya que se empleaba un $70.8 \%$ de esta y acumulación de inventarios en más del 90\% de algunos subsectores. Por el contrario, sólo hubo crecimiento positivo de 5 subsectores entre un total de 29 (ANDI, 1999, p. 8).

La pérdida de los niveles de producción se produjo debido al debilitamiento de la demanda interna, para solucionarlo se dirigieron los esfuerzos a incrementar el nivel de exportaciones, sin embargo, el dinamismo del sector exportador se relaciona con el dinamismo de la industria por lo que al presentarse la desaceleración, la iniciativa se obstaculizó.

Para detener la recesión de la economía se adopta un paquete de medidas dirigido a distintos frentes que a continuación se exponen de manera somera: el primero de ellos es controlar la inflación y disminuirla a menos de un dígito, este objetivo se logra en mayo de 1999 cuando se consigue un nivel del IPC de 9.98\%5; para elevar el nivel de competitividad se adoptó un política devaluacionista, la tasa de crecimiento del peso frente al dólar durante 1998 y hasta el 2002 fue en promedio del 17,24\%, al pasar la cotización de 1.427 pesos por dólar a 2.507 en el último año mencionado. Por último, para la recuperación de la inversión se disminuyeron las tasas de interés y en el año 2000 a través de la Ley 633 se creó el impuesto a las transferencias bancarias

5 Para detallar los resultados que la baja en el nivel de inflación generó en el nivel de empleo ver Maya, Guillermo (2000). 
conocido como el $3 * 1000$ con el propósito de recuperar y aumentar la solvencia del sistema financiero.

Finalmente estas medidas mejoraron, al menos en el mediano plazo, el comportamiento de la economía en su conjunto. La tasa del crecimiento del PIB en general y del sector manufacturero en particular volvió a crecer a pesar de que no lo hicieron a las mismas tasas de períodos anteriores, el PIB total creció en promedio durante 1998 y 2002 un 12,54\% mientras que el PIB industrial lo hizo a razón de $12,63 \%$. El volumen de exportaciones y el de importaciones se incrementa pero el primero lo hace a una tasa mayor lo que permite tener superávit en la balanza comercial entre 1999 y 2002 e inclusive el 2003.

El impacto de la crisis de fines de la década de los noventas implicó un aumento del nivel de importaciones y el cierre de varias empresas del sector debido al incumplimiento en el pago de las deudas a raíz de la subida de las tasas de interés, en consecuencia, para mantener los márgenes de ganancia los despidos aumentaron reflejándose en el aumento de la tasa de desempleo.

La anterior descripción del sector manufacturero en Colombia permite comprender su evolución y la razón por la cual esta industria dejó de ser el eje dinamizador de la economía colombiana, situación que se agudizó con la llegada del proceso de apertura a principios de los noventas. De esta manera, para que la transición al nuevo modelo se hiciera de la manera más acertada y rápida posible, fue necesario que los regímenes legales fueran modificados jurídicamente; estatutos como el General de Inversiones en 1991 que da igualdad en el trato tanto a inversionistas extranjeros como nacionales, o las Leyes 7 y 9 de 1991 que promueven la libertad comercial e iniciativa privada además de la adopción de tipo de cambio flexible como modalidad de convertibilidad de la moneda, fueron algunas de las medidas que se tomaron para la inserción de la economía colombiana al comercio internacional ${ }^{6}$.

Las anteriores modificaciones produjeron (además de lo escrito en apartes anteriores) un aumento en los flujos de IED en el país como se puede apreciar en la Figura 6.

$6 \quad$ Ley 7 y 9 de 1991. Disponible en: www.banrep.gov.co 
Figura 6. Stock de IED en Colombia

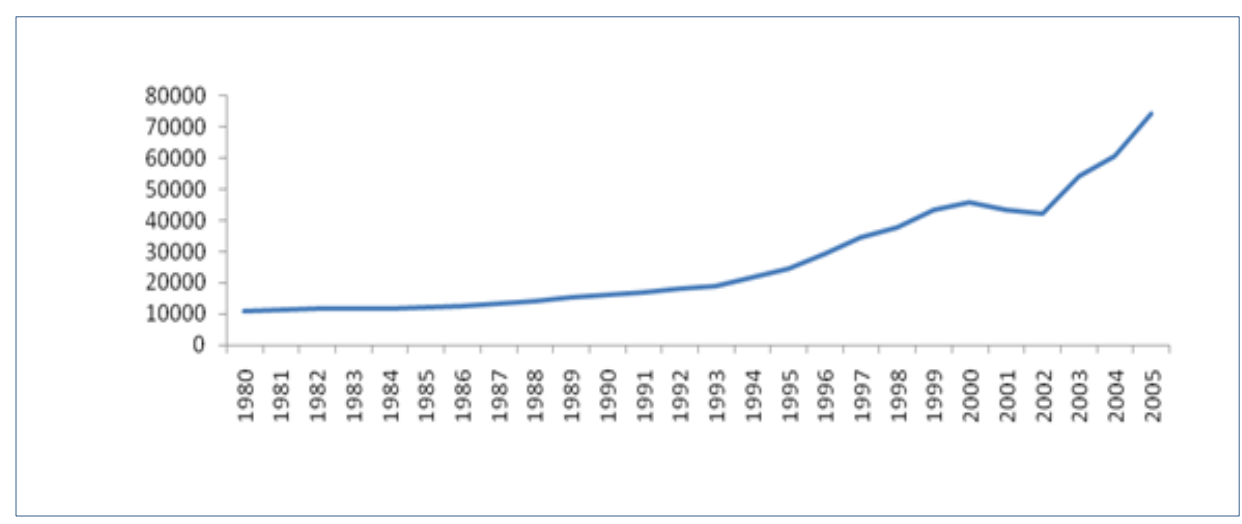

Fuente: UNCTAD. Cifras en Millones de Dólares.

Teóricamente el ingreso de Inversión Extranjera Directa ofrece ciertos beneficios como por ejemplo el aumento en el stock de capital del país en el que se invierte, el incremento en el flujo de divisas o externalidades generadas por los procesos de transferencia tecnológica; frente a este último tema han habido varios estudios que estiman los derramamientos de tecnología o spillovers de productividad entre las industrias receptoras y las empresas extranjeras. Para el caso colombiano, el estudio realizado por Atallah (2006) concluye que "los mecanismos de incrementos en la productividad de las empresas locales son generados por los nexos que las empresas transnacionales establecen con los proveedores nacionales" (p. 206).

A continuación se realiza una descripción de los flujos de Inversión Extranjera Directa a nivel mundial y de Colombia, enfatizando en la corriente de IED que ha llegado al sector manufacturero, para posteriormente pasar a la estimación de los determinantes de la IED.

\section{LA INVERSIÓN EXTRANJERA DIRECTA EN COLOMBIA}

\subsection{Comportamiento Sectorial de la IED en Colombia durante el Período 1978 - 2002}

En el caso de Colombia la IED ha estado dirigida principalmente al sector petrolero y minero, sin embargo, a mediados de los noventas esta tendencia varió y otros renglones ocuparon un puesto importante debido al relativo desarrollo del mercado interno y de las altas barreras arancelarias a mediados de los años setentas que incentivaron el ingreso de capital extranjero en el sector manufacturero del país. Tal como lo muestra la figura siguiente, alrededor del 65\% de la IED se concentraba en la industria manufacturera durante los años de 1979 y 1985, seguida del sector minero y del financiero con aproximadamente el 14\% y el 10\%, respectivamente. 
Figura 7. Tasa de Crecimiento de la IED en Colombia

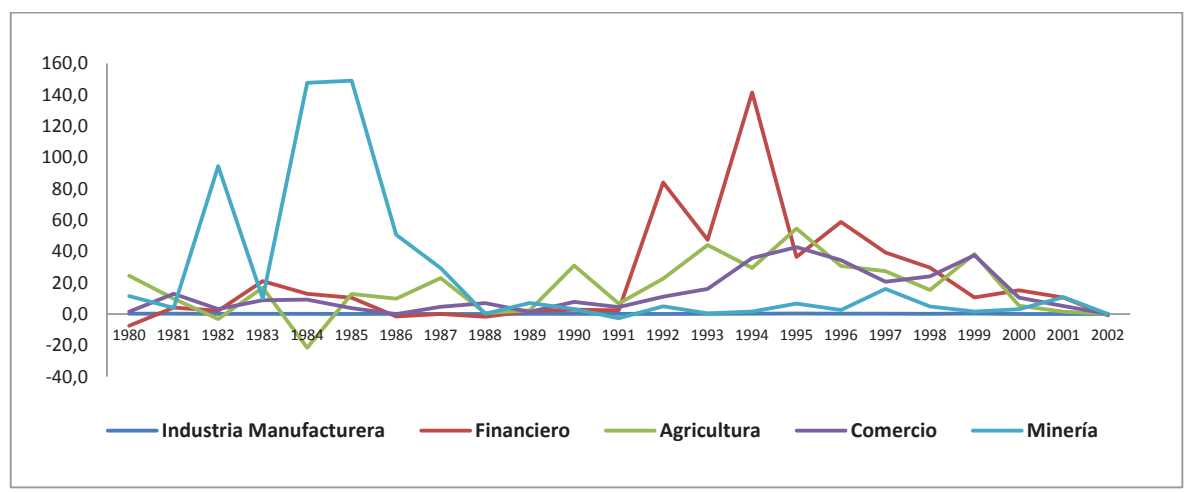

Fuente: DNP .

Los cambios ocurridos a raíz del proceso de apertura modifican el patrón de inversión en el país. Entre 1997 y 2002 la participación porcentual del sector manufacturero pierde alrededor de 30 puntos porcentuales, mientras que el sector financiero y los servicios públicos ganan participación, el primero gana alrededor del doble de participación y el segundo sector aumenta su participación en 14 puntos, lo anterior se debe principalmente al proceso de desindustrialización que se explicó en apartados anteriores y a las privatizaciones de activos del sector público tales como electrificadoras, bancos y empresas de telecomunicaciones.

Figura 8a. Composición sectorial de la IED en Colombia: 1979-1985

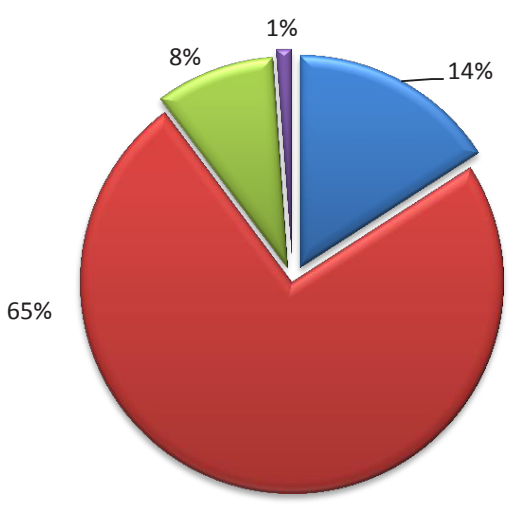

- Minería

Industria

$\square$ Comercio

Agricultura

Fuente: Banco de la República y DNP (2010) 
Figura 8b. Composición sectorial de la IED en Colombia: 1997-2002

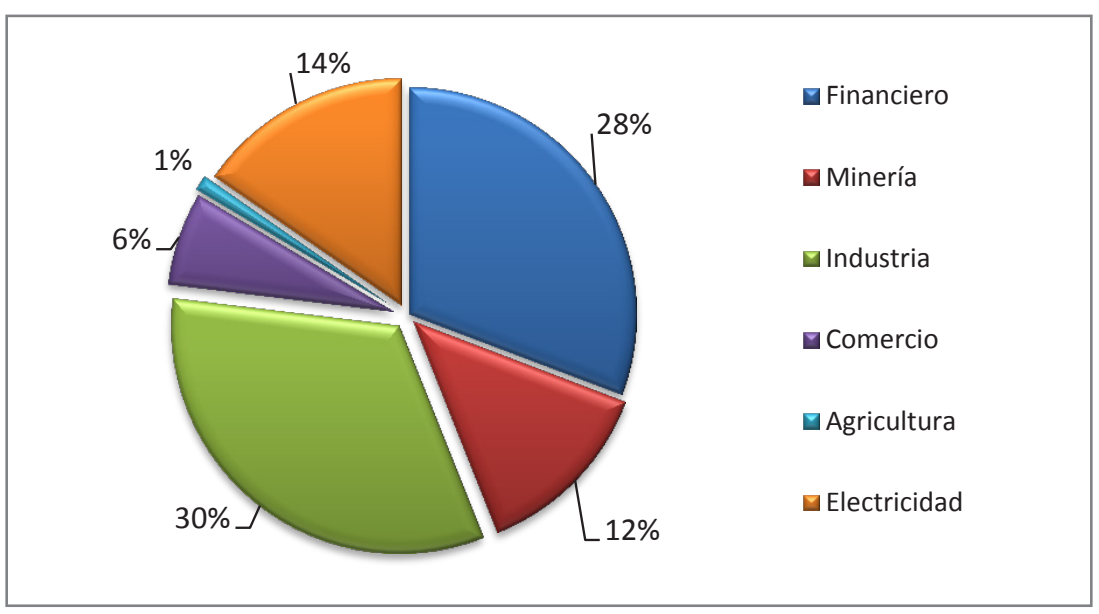

Fuente: Banco de la República y DNP (2010).

La tasa de crecimiento de la IED en el sector manufacturero colombiano se mantiene en promedio alrededor del 13\% entre 1978 y 2002, junto con el sector agropecuario $(16,6 \%)$ comportan los niveles más bajos de crecimiento. Por el contrario, el sector financiero y el sector de transporte y comunicaciones crecieron alrededor de $22,6 \%$ y $33 \%$ respectivamente, durante el mismo período.

Figura 9a. Participación de la Industria Manufacturera dentro de los Flujos de IED 1990-1994

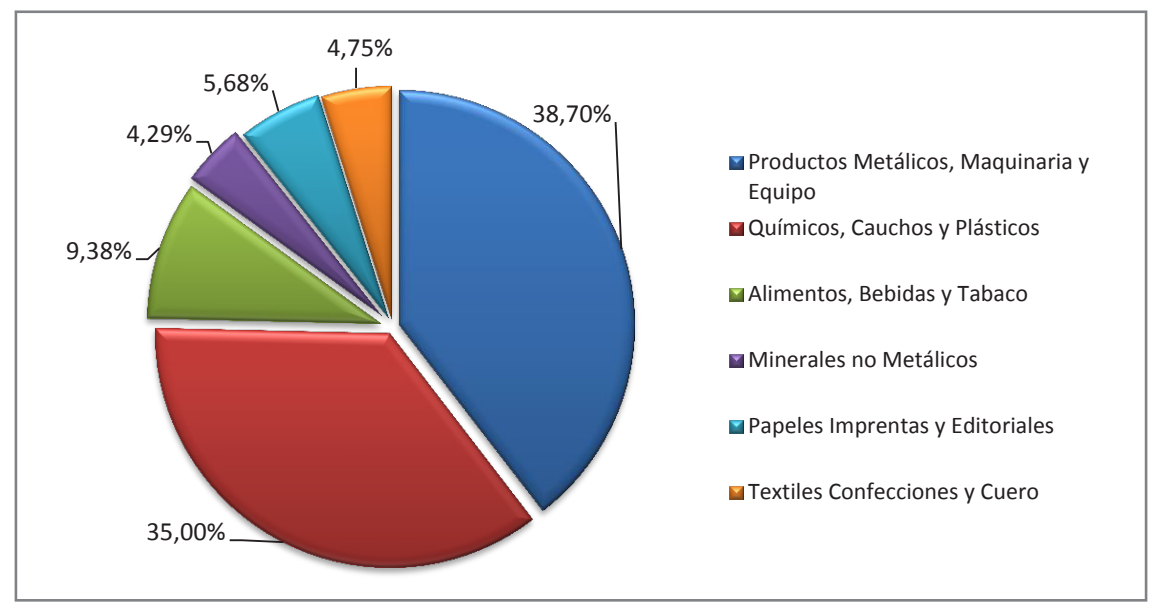

Fuente: Banco de la República- ANDI. 
Figura 9b. Participación de la Industria Manufacturera dentro de los flujos de IED 1995-1997

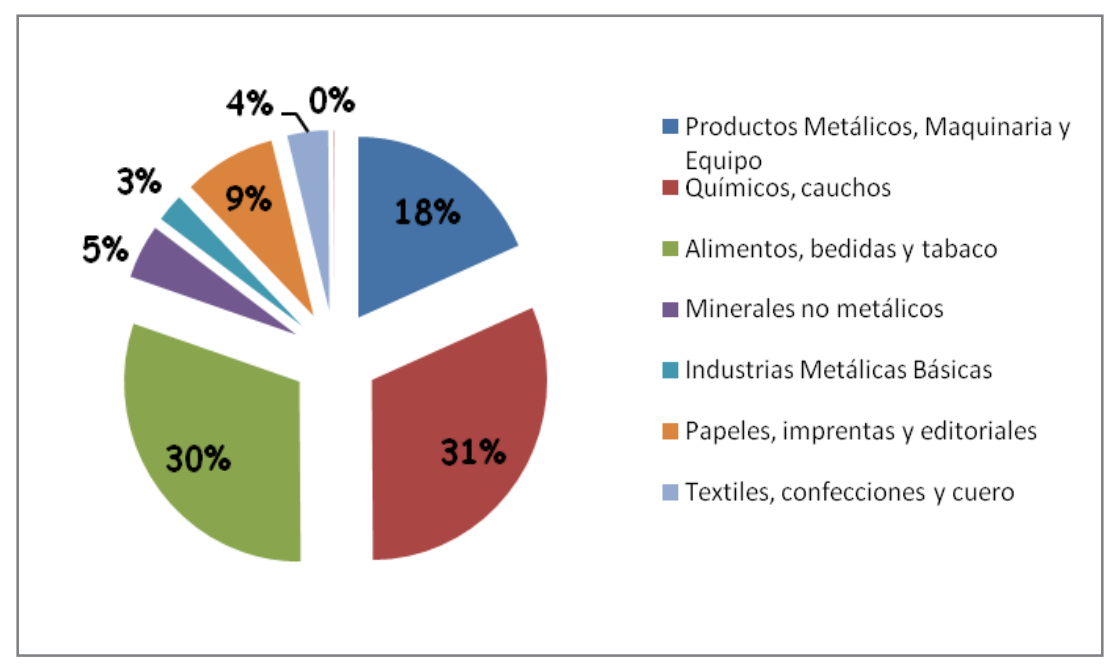

Fuente: Banco de la República- ANDI.

Figura 9c. Participación de la Industria Manufacturera dentro de los Flujos de IED 2000-2005

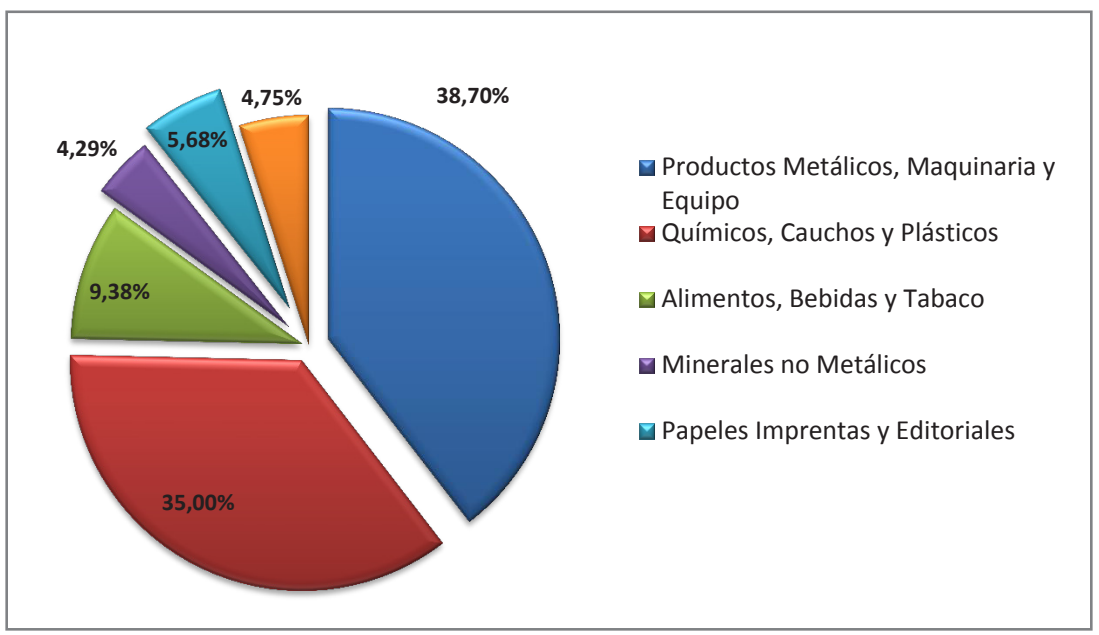

Fuente: Banco de la República- ANDI. Los valores de 2003 a 2004 son proyectados. 
A nivel de subsectores en la industria manufacturera, a pesar que hay variaciones en los ingresos de IED, se pueden observar la permanencia de determinadas ramas a lo largo del período de análisis. La rama de fabricación de productos y sustancias químicas mantiene una importancia relativa a pesar de que a principios de la década del noventa su participación era del 24\% y cae a 17\% entre el 2001 y el año 2002 . Lo contrario sucede con el sector de alimentos y bebidas debido a que su participación, dentro de los flujos de ingreso de IED, se incrementa en este mismo período pasando de $8 \%$ a $47 \%$. Un subsector que tiene una pérdida considerable es el de productos metálicos, maquinaria y equipo que entre 1990 y 1993 abarcaba un poco más de la mitad de los flujos de IED para ya en los años 2001 y 2002 disminuir su participación a menos de $5 \%$.

Los renglones que se mantienen son los de fabricación de prendas de vestir y la fabricación de productos textiles, y el subsector de papeles e imprenta, cada una con el $8 \%$ y $9 \%$ del total de flujos aproximadamente.

\subsection{Aproximación Teórica a los Determinantes de la IED}

Uno de los fenómenos que ha llamado la atención a raíz del proceso de globalización ${ }^{7}$ acaecido en la década de los noventas es el proceso de transnacionalización de las empresas a través de la inversión directa en activos en distintos países destino. El mencionado proceso es lo que se conoce como inversión extranjera. Esta puede ser de dos tipos, directa o de cartera. La primera se caracteriza por la movilidad de activos reales, sea capital, trabajo, tecnología y porque el retorno de la inversión se da en el largo plazo; la inversión extranjera de cartera se caracteriza porque su rentabilidad es de corto plazo y está dirigida especialmente al sector financiero. En este estudio se hará énfasis al primer tipo de inversión haciendo hincapié en la dirigida al sector manufacturero.

Diversos trabajos realizados para explicar los principales motivos de la transnacionalización (Altar Tur, 2002; Vallejo y Aguilar, 2004), se basan fundamentalmente en el Paradigma Ecléctico de Dunning desarrollado en la década de los setentas. Según este paradigma y sus primeros acercamientos teóricos, para que una empresa considere que es mejor invertir directamente en el extranjero en lugar de comerciar sus productos o servicios deben existir tres elementos:

Que la empresa tenga o pueda adquirir activos que otras empresas no estén en condiciones de adquirir; que le convenga más internalizar esos activos que venderlos o adquirirlos, y que prefiera asociarse con los recursos locales del país receptor en vez de hacerlo con los del país de origen (Martínez, 1991, p. 26)

7 Caracterizado por un mercado mundial único y por una importancia mayor del entorno internacional que del nacional. 
Los dos primeros elementos hacen referencia a las ventajas adquiridas por las empresas; los activos que posee una empresa y que las otras no están en capacidad de producir se refieren a las ventajas de propiedad, por ejemplo, contar con trabajadores altamente cualificados, poseer un tamaño de planta o de mercado mayor que posibilite disminuir el costo unitario del bien o del servicio o tener una marca consolidada en el mercado. La internalización es un elemento más complejo porque se relaciona directamente con las particularidades de los principales activos que poseen las empresas transnacionales basados en capital-conocimiento (AltarTur, 2002)-bienes tecnológicos y activos intangibles-.

En efecto, por ser el conocimiento un tipo de bien público, no excluyente y no rival, la venta al exterior de bienes y servicios por parte de las transnacionales hace fácilmente transferible y asimilable las ventajas que en materia de propiedad haya adquirido una empresa, generando una pérdida en el poder de mercado de las empresas transnacionales. Por lo tanto, las ventajas de internalización dirán por qué la compañía preferirá emprender ella misma la producción en el extranjero en vez de vender o licenciar los conocimientos que posee y que le otorgan una posición preferencial en el mercado (Martínez, 1991).

Por último, la preferencia a asociarse con activos de otros países se refiere a las ventajas de localización que poseen los países que albergarán la inversión, hay ventajas o determinantes de tipo tradicional como los recursos naturales, la búsqueda de mercados o la búsqueda de mano de obra a bajo costo. Otro tipo de ventajas se han desarrollado debido a que los avances tecnológicos se han convertido en una de las herramientas más importantes para competir en el contexto de la globalización, según la UNCTAD (1998) este tipo de ventajas promueven estrategias de integración complejas:

In other words, firms can increasingly seek locations where they can combine their own mobile assets most efficiently with the immobile resources they need to produce goods and services for the markets they want to serve. As a consequence, firms split up the production process into various specific activities (such as finance, R\&D, accounting, training, parts production, distribution), or segments of these activities, with each of them carried out by affiliates in locations best suited to the particular activity (UNCTAD, 1998, p. 111).

Por lo tanto, esta nueva tendencia en los determinantes económicos para la localización de la IED consiste en activos creados (createdassets) que son esencialmente el acceso a la tecnología y la capacidad innovadora. Lo anterior significa que las nuevas ventajas que buscan las empresas transnacionales no se basan solamente en ventajas de tipo tradicional (mercados, eficiencia y reducción de costos), sino en la combinación óptima entre éstas y las que se pueden crear. 


\section{PRINCIPALES DETERMINANTES ECONOMICOS EN PAISES RECEPTORES DE IED}
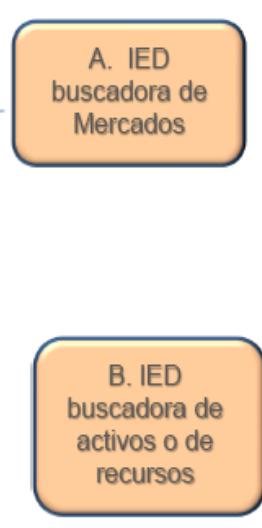

C. IED buscadora de Eficiencia
- Tamaño de Mercado e Ingreso per câpita. - Crecimiento de Mercado -Acceso a mercados Regionales y Globales. -Preferencias del consumidor en un pais especifico.

-Materia Prima.

-Mano de obra poco calificada.

- Tecnologia, innovación u otros activos creados -Infraestructura Fisica.

- Costo de los recursos y activos nombrados en $\mathrm{B}$, ajustados por la productividad.

-El costo de otros insumos, transporte y comunicaciones.

-Pertenencia a un acuerdo de integraciôn regional.

Fuente: UNCTAD (1998, p. 91) (Traducción propia).

En suma el Modelo Ecléctico de Dunning propone tres determinantes o ventajas que poseen las firmas para que se prefiera invertir directamente en otro país en vez de exportar: las ventajas de propiedad, las ventajas de internalización y las ventajas de localización. Dentro de estas últimas, las transnacionales se ubicarán en aquellos países que posean tanto ventajas de tipo tradicional, como en aquellos que hayan "creado sus activos" u otras condiciones gracias a la tecnología, el manejo técnico y la innovación, con el propósito principal incrementar la competitividad.

Empleando el enfoque del Modelo Ecléctico de Dunning (lo que se intenta responder es: cuáles han sido los determinantes que más influyen a las corporaciones transnacionales para invertir en el sector manufacturero colombiano. Para lo anterior, se construye un modelo econométrico que permite hacer una estimación empírica de los principales determinantes. 


\subsection{Estimación Empírica}

Para hacer la estimación empírica sobre los determinantes de la inversión extranjera directa (IED) en el sector manufacturero colombiano, se utilizan datos de series de tiempo con una frecuencia anual abarcando el periodo comprendido entre 1978 y 2002.

La variable dependiente es entonces la Inversión Extranjera Directa en el sector manufacturero colombiano en términos reales (IER). Esta fue tomada de los registros de IED del Banco de la República y equivale a los saldos a finales de diciembre de cada año;la variable está medida en millones de dólares y se pasó a pesos multiplicándola por la tasa de cambio nominal, por último, se deflactó por el Índice de Precios al Producto (IPP) al por mayor.

Las estimaciones sobre determinantes de la IED que otros autores han planteado (Chudnovsky y López, 2002; Mogrovejo, 2005) emplean como variables explicativas componentes de tipo macro y microeconómico, componentes de tipo político y social. Estos últimos quedan por fuera del alcance del estudio debido a la poca obtención de datos.

Haciendo esta salvedad, se tienen como variables de tipo macroeconómico el PIB per-cápita (Y) que permite tener una medida del tamaño de mercado y del nivel de ingresos de la economía destino. Esta variable fue obtenida de los datos de la Comisión Económica para América Latina y el Caribe (CEPAL), medida en millones de dólares a precios constantes del 2000. Como medida de la estabilidad macroeconómica se escoge la inflación (P), esperando un signo (-). Esta variable fue tomada del Banco de la República para los meses de diciembre de cada año.

Una depreciación de la moneda local permitiría un abaratamiento de las mercancías a exportar para las empresas extranjeras con vocación exportadora, para observar el efecto que tiene el grado de vocación exportadora de un país sobre los flujos de IED se escogió la variable tipo de cambio real (TCR). Esta se obtuvo de la base de datos de la CEPAL. Una aproximación del riesgo país se estimó dividiendo la Cuenta Corriente entre el PIB total de la economía ${ }^{8}$ (CC).

Como componente de tipo microeconómico se propuso para la estimación de los determinantes, la variable del costo salarial unitario (WPC) que muestra los costos

8 "La literatura de los años ochenta y noventa (Krugman, 1995) acepto esta definición como una buena proxy y advirtió que cuando esa proporción excede el 4\%, el riesgo país se incrementa rápidamente debido a que emerge de igual la amenaza del default, o de una crisis financiera y de largo plazo" (Dussel y Peters, 2007, p. 48). 
salariales por unidad de producto. Esta variable es la suma de los sueldos y salarios más prestaciones dividida entre el volumen de producto. Se obtuvo de la Encuesta Anual Manufacturera del Departamento Nacional de Estadística (DANE).

La regresión a estimar es la siguiente:

$$
\mathrm{IER}_{\mathrm{t}}=\mathrm{c}+\beta_{1} \mathrm{Y}_{\mathrm{t}}+\beta_{2} \mathrm{CC}_{\mathrm{t}}+\beta_{3} \mathrm{P}_{\mathrm{t}}+\beta_{4} \mathrm{TCR}_{\mathrm{t}}+\beta_{5} \mathrm{WPC}_{\mathrm{t}}+\mathrm{e}_{\mathrm{t}}
$$

Previo al Test de Cointegración se calcularon los test de raíces unitarias para las series LIER, LY, LWPC, LTCR, CC y DLP. Se encontró que las tres primeras variables son integradas de orden $1 \mathrm{I}(1)$, mientras que las dos últimas son integradas de orden $0 \mathrm{I}(0)$.

\section{Test de Cointegración de Johansen (Ver Anexo 1)}

Dados los resultados de integrabilidad de las series, el Test de Cointegración de Johansen se hará con las variables I(1), esto es LIER, LY, LTCR y LWPC. Este test indica que existe al menos un vector de cointegración; uno de los vectores es:

$$
L I E R=4.4 L Y+-0.22 L T C R+0.06 L W P C
$$

Se observa que los coeficientes de las variables LTCR y LWPC no son significativas de acuerdo al estadístico t calculado de 0.82 para el coeficiente LTCR y de -0.5 para LWPC. Imponiendo la restricción de que estos coeficientes son cero el vector restringido queda como:

\section{LIER $=9.11 \mathrm{LY}$}

Lo cual, en el largo plazo muestra que el determinante de la IED en el sector manufacturero es el producto.

Para estimar el Modelo de Corrección de Errores (MCE) se convirtieron las variables I(1) en variables integradas de orden $0-\mathrm{I}(0)-$. Con la estimación del modelo de corto plazo se escogieron las variables significativas para el modelo. 
Tabla 2. Modelo de Corrección de errores

\begin{tabular}{|c|c|c|c|c|}
\hline \multicolumn{5}{|c|}{ Dependent Variable: DLIER } \\
\hline \multicolumn{5}{|c|}{ Method: Least Squares } \\
\hline \multicolumn{5}{|c|}{ Sample(adjusted): 19802002} \\
\hline \multicolumn{5}{|c|}{ Included observations: 23 after adjusting endpoints } \\
\hline Variable & Coefficient & Std. Error & t-Statistic & Prob. \\
\hline $\mathrm{C}$ & -1.174 .294 & 5.572 .551 & -2.107 .283 & 0.0613 \\
\hline DLIER(-1) & 0.392600 & 0.220037 & 1.784 .242 & 0.1047 \\
\hline DLY & -0.046470 & 0.896219 & -0.051851 & 0.9597 \\
\hline $\operatorname{DLY}(-1)$ & 0.181121 & 1.125 .551 & 0.160918 & 0.8754 \\
\hline DLTCR & -0.701499 & 0.237659 & -2.951 .707 & 0.0145 \\
\hline DLTCR(-1) & 0.786063 & 0.351180 & 2.238 .347 & 0.0491 \\
\hline DLWPC & -0.973229 & 0.377678 & -2.576 .879 & 0.0276 \\
\hline DLWPC(-1) & 0.168699 & 0.272147 & 0.619881 & 0.5492 \\
\hline $\mathrm{CC}$ & $2.79 \mathrm{E}-06$ & $1.19 \mathrm{E}-05$ & 0.233705 & 0.8199 \\
\hline $\mathrm{CC}(-1)$ & $1.31 \mathrm{E}-05$ & $1.95 \mathrm{E}-05$ & 0.671984 & 0.5168 \\
\hline $\mathrm{CI}(-1)$ & -0.415940 & 0.197717 & -2.103 .718 & 0.0617 \\
\hline DLP & -2.004 .019 & 0.833037 & -2.405 .678 & 0.0370 \\
\hline $\operatorname{DLP}(-1)$ & 0.788721 & 0.707865 & 1.114 .224 & 0.2912 \\
\hline R-squared & 0.850776 & Akaikeir & criterion & -2.806 .778 \\
\hline Log likelihood & 4.527 .795 & Schwar & riterion & -2.164 .977 \\
\hline Durbin-Watson & 2.765 .728 & $\operatorname{Prob}(\mathrm{F}$ & tatistic) & 0.009656 \\
\hline
\end{tabular}

Fuente: Autor.

La tabla anterior muestra los resultados del MCE. El $\mathrm{R}^{2}$ de 0.85 significa que las variablesindependientes explican en un alto porcentaje $(85 \%)$ las variaciones de la dependiente. Paralelamente, se observan que son poco significativas para la regresión en el corto plazo la CC, CC(-1), P(-1), WCP(-1), DLP(-1), Y(-1), Y.

Así se obtienen las variables que más influyen en la determinación de la IED. Los resultados de la estimación final son los que se muestran a continuación: 


\section{Tabla 3. Tabla Final}

\begin{tabular}{|c|c|c|c|c|}
\hline \multicolumn{5}{|c|}{ Dependent Variable: DLIER } \\
\hline \multicolumn{5}{|c|}{ Method: Least Squares } \\
\hline \multicolumn{5}{|c|}{ Sample (adjusted): 19802002} \\
\hline \multicolumn{5}{|c|}{ Included observations: 23 after adjusting endpoints } \\
\hline Variable & Coefficient & Std. Errort & t-Statistic & Prob. \\
\hline $\mathrm{C}$ & -1.011 .521 & $1.616 .09-9$ & 6.259 .028 & 0.0000 \\
\hline $\operatorname{DLIER}(-1)$ & 0.315895 & 0.128398 & 2.460 .273 & 0.0256 \\
\hline DLTCR & $-0,649299$ & 0.197502 & -3.287 .563 & 0.0046 \\
\hline $\operatorname{DLTCR}(-1)$ & 0.542315 & 0.184779 & 2.934 .940 & 0.0097 \\
\hline DLWPC & -0.807086 & 0.192324 & -4.196 .499 & 0.0007 \\
\hline DLP & -1.103 .065 & 0.335334 & -3.289 .449 & 0.0046 \\
\hline $\mathrm{CI}(-1)$ & -0.359811 & 0.056902 & -6.323 .348 & 0.0000 \\
\hline R-squared & 0.771609 & \multicolumn{2}{|c|}{ Akaikeinfocriterion } & -2.902 .908 \\
\hline Log likelihood & 4.038 .344 & \multicolumn{2}{|c|}{ Schwarzcriterion } & -2.557 .323 \\
\hline Durbin-Watson & 2.564 .884 & \multicolumn{2}{|c|}{ Prob(F-statistic) } & \\
\hline
\end{tabular}

*Variables significativas al 95\%donde: CI = LIER -9.1LY

$$
\begin{gathered}
\text { DLIER }=-10.11+0.3158 \text { DLIER }(-1)-0.6492 \mathrm{DLTCR}+0.5423 \mathrm{DLTCR}(-1) \\
-0.8070 \text { DLWPC }-1.1030 \mathrm{DLP}-0.3598 \mathrm{CI}(-1)
\end{gathered}
$$

En términos estadísticos las variables tienen un $\mathrm{t}$ estadístico alto (en valor absoluto son mayores a dos) y un $\mathrm{R}^{2}$ alto permitiendo concluir que el modelo obtenido es válido para explicar las variables que tienen mayor impacto en la atracción de inversión extranjera directa en el sector manufacturero.

Como primer resultado se observa que un determinante esencial en el largo plazo es el tamaño del mercado interno lo cual va en concordancia con la teoría; mientras que en el corto plazo la IED aparece determinada por la tasa de crecimiento de los costos salariales, por la tasa de devaluación real y por la tasa de inflación. Se destaca el impacto de la tasa de inflación, el cual es grande y negativo; evidenciando la importancia de la estabilidad macroeconómica como determinante de los flujos de inversión.

Se observa que en el corto plazo el crecimiento de los costos salariales en el sector manufacturero no estimula la IED.

El efecto de la tasa de cambio real es doble: por una parte hay un efecto negativo sobre la IED, ya que encarece los insumos importados lo cual desestimularía la entrada de IED. Este es un efecto inmediato pero posteriormente la devaluación tiene 
un efecto estimulante en la IED al favorecer la actividad exportadora y proteger el mercado doméstico.

En el MCE la variable CI(-1) muestra el impacto del desequilibrio entre los flujos de IED en el sector manufacturero y su nivel óptimo dado por 9.1LY.

En suma, los resultados encontrados no se oponen a lo propuesto por la teoría, ya que en la mayoría de países de América Latina las inversiones extranjeras directas están dirigidas a la búsqueda de mercados alternativos que posibiliten mantener o aumentar las ganancias de las transnacionales.

\section{CONCLUSIONES}

El incremento de los flujos y del stock de la IED a nivel mundial y nacional hace importante el análisis de este fenómeno desde diferentes enfoques. El punto de partida de este estudio se basó en una comprensión histórica de los principales factores que dinamizaron la desindustrialización del sector manufacturero colombiano, los cuales consistieron en una acumulación de tipo extensivo; la búsqueda de rentabilidad en el corto plazo a través del sistema financiero; shocks de carácter internacional como los petroleros; la crisis financiera ocurrida a mediados de los ochentas, entre otros.

Por otra parte, la adopción del modelo volcado al mercado exterior a principios de la década de los noventas debilitó el entramado del sector industrial manufacturero en Colombia debido a que el país no contaba con un sector de bienes transables consolidado. Sin embargo, hay ciertos sectores que han mantenido el nivel de competitividad durante el período de estudio, estos son el sector de químicos, de alimentos y bebidas y algunos productos del subsector de bienes de capital.

Debido a los efectos que en materia de competitividad y de productividad se adeudan a la IED, la estimación empírica acerca de los determinantes sobre la IED en el sector manufacturero colombiano permite concluir que las variables que determinan el ingreso de estos flujos de IED son principalmente los costos salariales, el tipo de cambio, la inflación y en el largo plazo el tamaño del mercado. Esta última tiene una estrecha relación con el proceso industrializador colombiano, ya que los altos niveles arancelarios y la vocación de la producción hacia el mercado interior condujeron a la IED a mantener este patrón de comportamiento.

De esta manera, este estudio permite entender la lógica de la IED que se dirige al sector manufacturero, ésta tiene un comportamiento estrecho con el proceso industrializador colombiano.

\section{REFERENCIAS}

Altar Tur, A. (2002). Inversión Extranjera Directa OCDE-Argentina: Un análisis de sus Factores Determinantes y su Relación con los Flujos Comerciales. Tesis de Doctorado, Departamento de Economía Aplicada. Valencia (España): Universidad de Valencia. 
ANDI. (1996). ¿Para Dónde va la Economía Colombiana? Revista ANDI(13).

ANDI. (1999). Industrialización y Desindustrialización en Colombia, en: Revista ANDI (156),

Atallah M, S. (2006). Revaluando la Transmisión de Spillovers de la IED: un estudio de productividad para Colombia. Desarrollo y Sociedad (57), 163-213.

Benavente, J. M., G. Crespi, et al. (1996). Nuevos Problemas y Oportunidades en el Desarrollo Industrial de América Latina. Cuadernos de Economía, 15 (25), 33-68.

Bonilla, M. G. (1998). Apertura Económica y Transformación Productiva en la Industria Manufacturera Colombiana, 1987-1995. Planeación y Desarrollo, 29(1), 73-116.

Castrillón R., G. P. (2007). Efectos de la Inversión Extranjera Directa sobre el Crecimiento en la Economía Colombiana 1970-2003. Tesis de Maestría, Escuela de Economía. Medellín: Universidad Nacional de Colombia.

Chica Avella, R. (1994). Crisis y Reconversión en la Industria Colombiana. Bogotá: Pontificia Universidad Javeriana.

Chudnovsky, D. y López, A. (2002). Integración Regional e Inversión Extranjera Directa. El caso Mercosur. Argentina: Serie Intal, BID-INTAL.

DANE. Cuentas Nacionales, DANE.

DNP. Departamento Nacional de Planeación 1977.

Doryan, G. E. (1992). Economía y Reconversión Industrial. Conceptos, Políticas y Casos. Ecuador: Instituto Centroamericano de Administración de Empresas y Programa de Estudios y Entrenamiento Económico

Dussel, P. (2007). La Inversión Extranjera Directa en México: Desempeño y Potencial. México: Universidad Autónoma de México, Siglo XXI.

Echavarría, J. J. y Villamizar, M. (2007). El Proceso Colombiano de Desindustrialización. En M. Urrutia y J. Robinson (Eds.), La Economía Colombiana del Siglo XX. Un análisis cuantitativo (pp. 173-229). Bogotá: Fondo de Cultura Económica y Banco de la República.

Echeverry G., J. C. (1999). La Recesión de Fin de Siglo en Colombia: flujos, balances y política anticíclica. Planeación y Desarrollo 30 (2), 93-148

Fatat, A. (1998). Inversión Extranjera, Exportaciones e Innovación Tecnológica en la Industria Colombiana, 1992-1997. Planeación y Desarrollo 29 (1), 117-148.

Gachino, G. (2012). Technological spillovers from multinational presence. Towards A Conceptual Framework. International Journal of Business and Management 7 (9), 158-174.

Guerra-Borges, A. (2001). Factores Determinantes de la Inversión Extranjera: introducción a una teoría inexistente. Comercio Exterior 15(9), 825-832.

Hernández, G. and J. M. Ramírez (1999).Complementariedades Factoriales y Cambio Técnico en la Industria Colombiana. Planeación y Desarrollo 30(2), 149-168. 
Jessop, B. (1999). ¿Hacia un Estado de Trabajo Schumpeteriano? Crisis del Estado de Bienestar: Hacia una nueva teoría del Estado y sus consecuencias sociales. Bogotá: Universidad Nacional de Colombia, Siglo del Hombre.

Kalmanovitz, S. (1988). Colombia: la Industrialización a Medias. Cuadernos de Economía 9(12), 71-89

Martínez, A. (1996). Inversión extranjera directa \& otras formas de financiamiento externo. Universidad Nacional de Colombia.

Martínez, A. (1991). Hipótesis sobre los Determinantes de la Inversión Extranjera. Cuadernos de Economía 11(16), 101-138.

Maya, G. (2000). Keynes, la Gran Crisis del 30 y la actual Recesión en Colombia. Revista Un aula (20), 75-93.

Misas Arango, G. (1985). Acumulación y Crisis en la Economía Colombiana. Cuadernos de Economía, 8 (8), 133-166.

Misas Arango, G. (2002). La ruptura de los 90 del gradualismo al colapso. Bogotá: Universidad Nacional de Colombia.

Mora R., L. (1984). Elementos Estructurales de la Recesión Industrial en Colombia. Cuadernos de Economía 6 (6), 121-143.

Motimore, M. (1995). América Latina Frente a la Globalización. Política Industrial y Desarrollo Tecnológico: Lecciones para el caso colombiano. (pp.161-192). Bogotá, Pontificia Universidad Javeriana.

Ortiz, C. H., J. I. Uribe, et al. (2009). Transformación Industrial, Autonomía Tecnológica y Crecimiento Económico: Colombia 1925-2005. Archivos de Economía

Perry, G. (1989). La Economía Colombiana, desde 1979 hasta nuestros días. En J. A. Bejarano (Ed.), Nueva Historia de Colombia (pp. 189-212). Bogotá: Planeta.

Planeación, D. N. d. (1977). Industria Manufacturera, en Planeación y Desarrollo 9 (3), 183-226.

Poveda R., G. (2005). El Mal Decenio Final. Historia Económica de Colombia en el Siglo XX, pp. 683-728. Medellín: U. P. Bolivariana.

Poveda R., G. (2002). El Mal Decenio Final. Historia Económica de Colombia en el Siglo $X X$, pp. 683-728. Medellín: U. P. Bolivariana.

Ramírez, M. y Silverman, J. (2007). Base de Datos “Multinacionales”. Medellín, Escuela Nacional Sindical.

República, B. d. 1. Series Estadísticas.

Steiner, R. and U. Giedion (1996). Características, Determinantes y algunos Efectos de la Inversión Extranjera Directa en Colombia, pp. 161-209, en Inversión Extranjera Directa en América Latina: su contribución al desarrollo. M. Agosín (Ed.). Chile: Fondo de Cultura Económica/ Banco Interamericano de Desarrollo.

UNCTAD. Foreign Direct Investment Database, UNCTAD. 
UNCTAD. (1998). World Investment Report 1998: Trend and Determinants, UNCTAD.

UNCTAD (2006).World Investment Report 2006. FDI from Developing and Transition Economies: Implications for Development. New York/ Geneva: UnitedNations.

Uribe, M. T. (1992). De la Ética de los Tiempos Modernos o del Retorno a la Virtudes Públicas. Estudios Políticos, (2), 7-25.

Vallejo, H. y Aguilar, C. (2004). Integración Regional y Atracción de Inversión Extranjera Directa: el caso de América Latina. Desarrollo y Sociedad (53)

Villamil, J. A. (1998). Colombia: Estructura Industrial e Internacionalización, 19671996”, en Planeación y Desarrollo, 29 (1), 257-322.

Zerda, A., [Ed.] (1992). Apertura, Nuevas Tecnologías y Empleo. Bogotá: Fundación Friedrich Ebert de Colombia -FESCOL-.

\section{ANEXOS}

Anexo 1. Test de Cointegración de Johansen

\section{Johansen Cointegration Test}

Date: 11/10/09 Time: 09:54

Sample(adjusted): 19802002

Included observations: 23 after adjusting endpoints

Trend assumption: Linear deterministic trend

Series: LIER LY LTCR LWPC

Lags interval (in first differences): 1 to 1

\section{UnrestrictedCointegration Rank Test}

\begin{tabular}{|c|c|c|c|c|}
\hline Hypothesized & EigenValue & Trace & 5 Percent & 1 Percent \\
\hline No. of CE(s) & Value & Statistic & CriticalValue & CriticalValue \\
\hline None $* *$ & 0.715422 & 5.863 .810 & 47.21 & 54.46 \\
\hline At most $1 *$ & 0.479054 & 2.973 .291 & 29.68 & 35.65 \\
\hline At most 2 & 0.327201 & 1.473 .442 & 15.41 & 20.04 \\
\hline At most $3 *$ & 0.216761 & 5.619 .311 & 3.76 & 6.65 \\
\hline \multicolumn{5}{|c|}{$\begin{array}{l}*(* *) \text { denotes rejection of the hypothesis at the } 5 \%(1 \%) \text { level } \\
\text { Trace test indicates } 2 \text { cointegrating equation(s) at the } 5 \% \text { level } \\
\text { Trace test indicates } 1 \text { cointegrating equation(s) at the } 1 \% \text { level }\end{array}$} \\
\hline
\end{tabular}




\begin{tabular}{|c|c|c|c|c|}
\hline Hypothesized & EigenValue & Max-Eigen & 5 Percent & 1 Percent \\
\hline \multicolumn{2}{|c|}{ No. of CE(s) } & Statistic & CriticalValue & CriticalValue \\
\hline None * & 0.715422 & 2.890 .519 & 27.07 & 32.24 \\
\hline At most 1 & 0.479054 & 1.499 .849 & 20.97 & 25.52 \\
\hline At most 2 & 0.327201 & 9.115 .107 & 14.07 & 18.63 \\
\hline At most $3 *$ & 0.216761 & 5.619 .311 & 3.76 & 6.65 \\
\hline \multicolumn{5}{|c|}{$\begin{array}{l}\text { Max-eigenvalue test indicates } 1 \text { cointegrating equation(s) at the } 5 \% \text { level } \\
1 \text { CointegratingEquations (Log likelihood } 173.1403)\end{array}$} \\
\hline LIER & LY & LTCR & LWPC & \\
\hline \multirow[t]{2}{*}{1.000 .000} & -4.408 .773 & 0.227055 & -0.066905 & \\
\hline & -183.641 & $(0.27717)$ & $(0.15190)$ & \\
\hline \multicolumn{5}{|l|}{ Restrictions: } \\
\hline \multicolumn{5}{|c|}{$b(1,1)=1, b(1,3)=0, b(1,4)=0$} \\
\hline \multicolumn{5}{|c|}{ Tests of cointegrationrestrictions: } \\
\hline Hypothesized & Restricted & LR & Degrees of & Probability \\
\hline No. of CE(s) & Log-likehood & Statistic & Freedom & \\
\hline 1 & 1.826 .514 & 3.727 .201 & 2 & 0.155113 \\
\hline 2 & 1.979 .155 & $*$ & $*$ & * \\
\hline 3 & 2.077 .636 & NA & NA & NA \\
\hline \multicolumn{5}{|c|}{$\begin{array}{l}\text { NA indicates restriction not binding. } \\
1 \text { Cointegrating Equation(s): Convergence achieved after } 140 \text { iterations. } \\
\text { Restricted cointegrating coefficients (std.err. in parentheses) }\end{array}$} \\
\hline LIER & LY & LTCR & LWPC & \\
\hline 1.000 .000 & -9.116 .995 & 0.000000 & 0.000000 & $\mathrm{VC}=\mathrm{LIER}-9.1 * \mathrm{LY}$ \\
\hline$(0.00000)$ & $(0.50011)$ & $(0.00000)$ & $(0.00000)$ & \\
\hline Adjustment & coefficients & (std.err. in pare & heses) & \\
\hline D(LIER) & -0.180494 & $(-0.02461)$ & & \\
\hline $\mathrm{D}(\mathrm{LY})$ & 0.031624 & $(-0.01275)$ & & \\
\hline D(LWPC) & 0.055789 & $(-0.04783)$ & & \\
\hline
\end{tabular}


Anexo 2. Subsectores de la Industria Manufacturera CIIU Rev. 2

\begin{tabular}{|c|c|}
\hline Código & Denominación \\
\hline $311 / 312$ & Fabricación de productos alimenticios, excepto bebidas \\
\hline 313 & Industria de bebidas \\
\hline 314 & Industria del tabaco \\
\hline 321 & Fabricación de textiles \\
\hline 322 & Fabricación de prendas de vestir, excepto calzado \\
\hline 323 & $\begin{array}{l}\text { Industria del cuero y productos de cuero, sucedáneos de cuero } \\
\text { y pieles, excepto prendas de vestir }\end{array}$ \\
\hline 324 & Fabricación de calzado, excepto el caucho vulcanizado o moldeado de plástico \\
\hline 331 & Industria de madera y productos de madera y corcho, excepto muebles \\
\hline 332 & Fabricación de muebles y accesorios excepto los que son principalmente metálicos \\
\hline 341 & Fabricación de papel y productos de papel \\
\hline 342 & Imprentas, editoriales e industrias conexas \\
\hline 351 & Fabricación de sustancias químicas industriales \\
\hline 352 & Fabricación de otros productos químicos \\
\hline 353 & Refinerías de petróleo \\
\hline 354 & Fabricación de productos diversos derivados del petróleo y del carbón \\
\hline 355 & Fabricación de productos de caucho \\
\hline 356 & Fabricación de productos de plástico n.c.p. \\
\hline 361 & Fabricación de objetos de loza, barro y porcelana \\
\hline 362 & Fabricación de vidrio y productos de vidrio \\
\hline 369 & Fabricación de otros productos minerales no metálicos \\
\hline 371 & Industrias básicas de hierro y acero \\
\hline 372 & Industrias básicas de metales no ferrosos \\
\hline 381 & Fabricación de productos metálicos exceptuando maquinaria y equipo \\
\hline 382 & Construcción de maquinaria exceptuando la eléctrica \\
\hline 383 & Construcción de maquinaria aparatos, accesorios y suministros eléctricos \\
\hline 384 & Construcción de material de transporte \\
\hline 385 & Fabricación de equipo profesional y científico, instrumentos de medida y de control n.c.p. \\
\hline 390 & Otras industrias manufactureras \\
\hline
\end{tabular}

Fuente: DANE- Código CIIU Clasificación Industrial Internacional Uniforme. 
Anexo 3. Series de Tiempo de las Variables del Modelo

\begin{tabular}{|c|c|c|c|c|c|c|}
\hline AÑO & $\mathrm{CC}$ & CSU & IER & IPC & TCR & PIBH \\
\hline 1978 & 330 & 120.291 .397 & 1158738.1 & 122.420 .324 & 85.47 & 172.973 .153 \\
\hline 1979 & 512 & 156.953 .192 & 1070875.81 & 152.586 .491 & 84.82 & 178.202 .286 \\
\hline 1980 & 104 & 208.608 .379 & 1057917.58 & 19.258 .741 & 82.23 & 181.397.711 \\
\hline 1981 & -1722 & 273.307.301 & 1167101.34 & 245.584 .198 & 76 & 181.495 .525 \\
\hline 1982 & -2885 & 368.868 .379 & 1212473.84 & 304.804 .462 & 71.32 & 179.277 .051 \\
\hline 1983 & -2826 & 458.043 .105 & 1380673.23 & 366.747 .497 & 72.95 & 178.230 .111 \\
\hline 1984 & -2088 & 590.226 .188 & 1608411.08 & 426.259 .487 & 77.41 & 180.346 .744 \\
\hline 1985 & -1586 & 673.460 .745 & 1931148.95 & 529.044 .083 & 102.41 & 182.115 .128 \\
\hline 1986 & 463.5 & 809.087 .527 & 2260256.89 & 628.571 .078 & 115.1 & 188.809 .554 \\
\hline 1987 & -205.480 .346 & 105.211 .156 & 2172643.49 & 775.697 .941 & 115.92 & 194.958 .844 \\
\hline 1988 & -215.660 .092 & 130.703 .175 & 2151644.78 & 993.179 .256 & 114.92 & 198.871 .845 \\
\hline 1989 & -200.981 .878 & 167.455 .413 & 2430778.33 & 125.062 .696 & 121.8 & 201.657 .236 \\
\hline 1990 & 543.400 .737 & 218.155 .548 & 2664581.7 & 161.416 .547 & 132.3 & 206.258 .203 \\
\hline 1991 & 234.650 .307 & 238.793 .743 & 2979867.52 & 21.049 .449 & 115.9 & 207.164 .609 \\
\hline 1992 & 875.707 .474 & 337.507 .437 & 3159384.76 & 267.380 .951 & 109.8 & 212.148 .457 \\
\hline 1993 & -221.929 .746 & 437.645 .933 & 3526849.19 & 327.384 .011 & 111.4 & 220.141 .885 \\
\hline 1994 & -311.259 .749 & 553.123 .723 & 3546872.73 & 402.177 .552 & 103.9 & 22.729 .095 \\
\hline 1995 & -438.763 .352 & 734.717 .543 & 4147789.67 & 486.209 .064 & 105.5 & 234.865 .675 \\
\hline 1996 & -478.447 .114 & 856.211 .098 & 5065993.38 & 587.319 .819 & 101 & 235.502 .294 \\
\hline 1997 & -5522.8 & 108.444 .926 & 5698817.37 & 695.807 .538 & 93.7 & 239.363 .878 \\
\hline 1998 & -485.792 .787 & 134.022 .358 & 7030410.96 & 825.777 .475 & 104.3 & 236.637 .078 \\
\hline 1999 & 670.860 .645 & 144.174 .047 & 10096694.3 & 915.560 .841 & 109.2 & 222.933 .715 \\
\hline 2000 & 73.426 .824 & 155.877 .609 & 11113398.6 & 100 & 122.2 & 225.758 .584 \\
\hline 2001 & -121.203 .759 & 167.010 .037 & 11684737.3 & 10.796 .756 & 115.5 & 227.063 .794 \\
\hline 2002 & -128.916 .092 & 177.633 .383 & 11904370.6 & 114.818 .407 & 134.1 & 229.075 .196 \\
\hline
\end{tabular}


Anexo 4. Principales Empresas Transnacionales en el Sector Manufacturero Colombiano

\begin{tabular}{|ccc|}
\hline ETN & PAÍS DE ORIGEN & SECTOR \\
\hline General motorscorp & Estados unidos & Automotriz \\
\hline Nestlé & Suiza & Agroindustria \\
\hline Dow chemical & Estados unidos & Químicos \\
\hline
\end{tabular}

Fuente: Peters, 2007. 
